\title{
Design of IMC-PID controller with fractional-order filter for steam distillation essential oil extraction process
}

\author{
Siti Nur Hasinah Binti Johari, Mohd Hezri Fazalul Rahiman, Najidah Hambali, Ramli Adnan, \\ Mazidah Tajjudin \\ Faculty of Electrical Engineering, Universiti Teknologi MARA, Shah Alam, Selangor, Malaysia
}

\begin{tabular}{l}
\hline \hline Article Info \\
\hline Article history: \\
Received Mar 15, 2020 \\
Revised May 4, 2020 \\
Accepted May 18, 2020 \\
\hline
\end{tabular}

Keywords:

CRONE

Essential oil extraction Fractional-order filter Internal model control Process control Steam distillation

\begin{abstract}
Essential oils are one of the industry's major compounds, particularly in the pharmaceutical, perfume and food sectors. They were acquired using several methods such as steam distillation. In this method, heat from the steam will release the aromatic molecule at their specific boiling points. Thus, it is important to regulate the steam temperature at the correct level to get the perfect composition of the yield. Many studies have shown that essential oil is volatile and sensitive to excess heat. In order to maintain the desired steam temperature, this study proposed an internal model control (IMC) based PID with fractional-order filter as a controller for this system. IMC is a modelbased control structure that can handle parameter variations and load disturbance very well. With the inverse model imposed in the loop, IMC can gain a perfect tracking control as well. The implementation of a fractionalorder filter cascaded to the PID controller may enhance the system robustness to process gain with its iso-damping properties. This study was conducted by simulation using MATLAB R2018. The step response of the closed-loop system has been evaluated with varying filter parameters depending on the desired phase margin of the open-loop reference model.
\end{abstract}

This is an open access article under the CC BY-SA license.

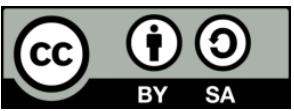

Corresponding Author:

Mazidah Tajjudin

Faculty of Electrical Engineering

Universiti Teknologi MARA (UiTM)

Shah Alam, Selangor, Malaysia

Email: mazidah@uitm.edu.my

\section{INTRODUCTION}

Essential oils are botanical substances that can be obtained through the extraction process of aromatic plants. Essential oils are primarily used in the flavour, fragrance, cosmetics and pharmaceutical industries [1-4]. The essential oils contain a complex mixture of volatile chemical compounds and they are sensitive towards temperature which may affect the quality of the oils [5-7]. Steam distillation is one of the effective and affordable methods used to maintain a strict temperature range. The essential oils will not be distilled if the temperature is too low and it will damage if the temperature is too high.

Steam distillation method can purify or isolate sensitive materials such as natural aromatic compounds, where steam is injected into the plant to release aromatic molecule. Moreover, steam distillation is the most popular method to be used in collection essential oil [8]. Almost 93\% of essential oils extracted using this method $[9,10]$. Furthermore, the advantage of steam distillation is that it can be precisely controlled and adjusted the temperature to ensure that the system remains consistent within the optimal temperature range [11]. It is also considered as a low-cost system, but able to improve productivity leading to industry preferences $[12,13]$. 
For many decades, the Proportional Integral Derivative (PID) controller has remained the largest used process control technique [12-16]. However, when the PID controller was tuned using a basic method, the control loop performance will be drifted if the parameter of control loop changed and load disturbance occurs, resulting in undesired results $[17,18]$. Therefore in 1980s, Morari et al. in [18-20] had introduced the PID tuning using Internal Model Control (IMC). IMC control structure can be decomposed into two transfer function; the PID controller and a simple filter equation. The first application of IMC was applied to the continuous distillation plant [18]. As the pioneer in the IMC, they had demonstrated the benefits of IMC control design in many processes. Li et al. in [21] had applied the Internal Model Control based PID (IMCPID) tuning method for superheated steam temperature control. In their research, the IMC PID was designed using the Skogestad-IMC (SIMC) tuning method [22] to achieve perfect setpoint tracking. Rao et al. [23] proposed an IMC-PID controller for integrating system with time delay. They used the estimation of firstorder Pade's for the time-delay term. The comparative studies had been made between servo and regulatory problem. The result shows that the proposed method gives better integral performance criteria in terms of ISE, IAE and ITAE.

In recent advancement, many researchers had included a fractional-order filter instead of an ordinary filter. This is because the filter give the advantage of iso-damping properties of a fractional-order function that is robust to gain variation. In [24, 25], Bettayeb and Mansouri studied the IMC-PID cascased with fractional-order filter controller design for integer order system. They had generalized the tuning rule for a different type of processes using CRONE principle. The processes that had studied were the liquid level system and angular velocity control a servo system. Both procecess show a good result in both setpoint tracking and disturbance rejection when applied the proposed design as the controller.

The main objective of this project is to design a new controller for steam distillation essential oil extraction process using IMC based PID controller with fractional-order filter to regulate the steam temperature and at the same time guarantee the robustness of the process towards disturbance and process parameters change. The controller design criteria was based on Bettayeb and Mansouri purposed in [25]. One of the controller design criteria is using the CRONE principle to achieve the design requirement specified by the desired phase margin and crossover frequency. The simulation was done by Simulink in MATLAB R2018 software to evaluate the performance of the closed-loop system for several sets of requirements.

\section{RESEARCH METHOD}

Figure 1 shows the flow chart of designing the controller. First of all, the literature review must be done before designing the controller because information of this research needs to be read and understand the context very well. Next are the ORA and IMC synthesis. ORA stands for Oustaloup Recursive Approximation that widely used as an open-loop reference to find a rational integer-order approximation for fractional-order integrators and differentiator [26]. ORA will affect the fractional-order filter inside the designed controller while IMC synthesis will affect the PID parameter of the system. Next from the derivation by using IMC controller design and fractional filter, the parameters of the controller are calculated. Then, design the block diagram of the system and run the simulation using MATLAB/Simulink. Every design had its own value for PID parameters and observed the step responses. Moreover, from this simulation, the reaction curve was observed by the characteristic of the curve. If the reaction curve is not meet the criteria, the parameter of the controller can be varied. Then if the reaction curve meets the criteria, the objective of designing the controller is achieved.

\subsection{Internal model control (IMC)}

The basic arrangement of IMC is shown in Figure 2 where $G_{m}(s)$ is the process and $G_{m}{ }^{\prime}(s)$ is the process model. If both process and its model is similar, it will result in the ability to estimate disturbance. In addition, the predicted disturbance is the actual disturbance when both processes are equal. The IMC controller can eliminate any disturbance from the setpoint, thus fulfilling the perfect control.

In order to derive the IMC algorithm, Figure 2 can be transformed equally into Figure 3 . Then, by simplifying the feedback loop within the dotted box, yields a transfer function of a controller in terms of $\mathrm{C}_{\mathrm{IMC}}(\mathrm{s})$ and $\mathrm{G}_{\mathrm{m}}{ }^{\prime}(\mathrm{s})$. Finally, the simplified IMC structure is shown in Figure 4. 


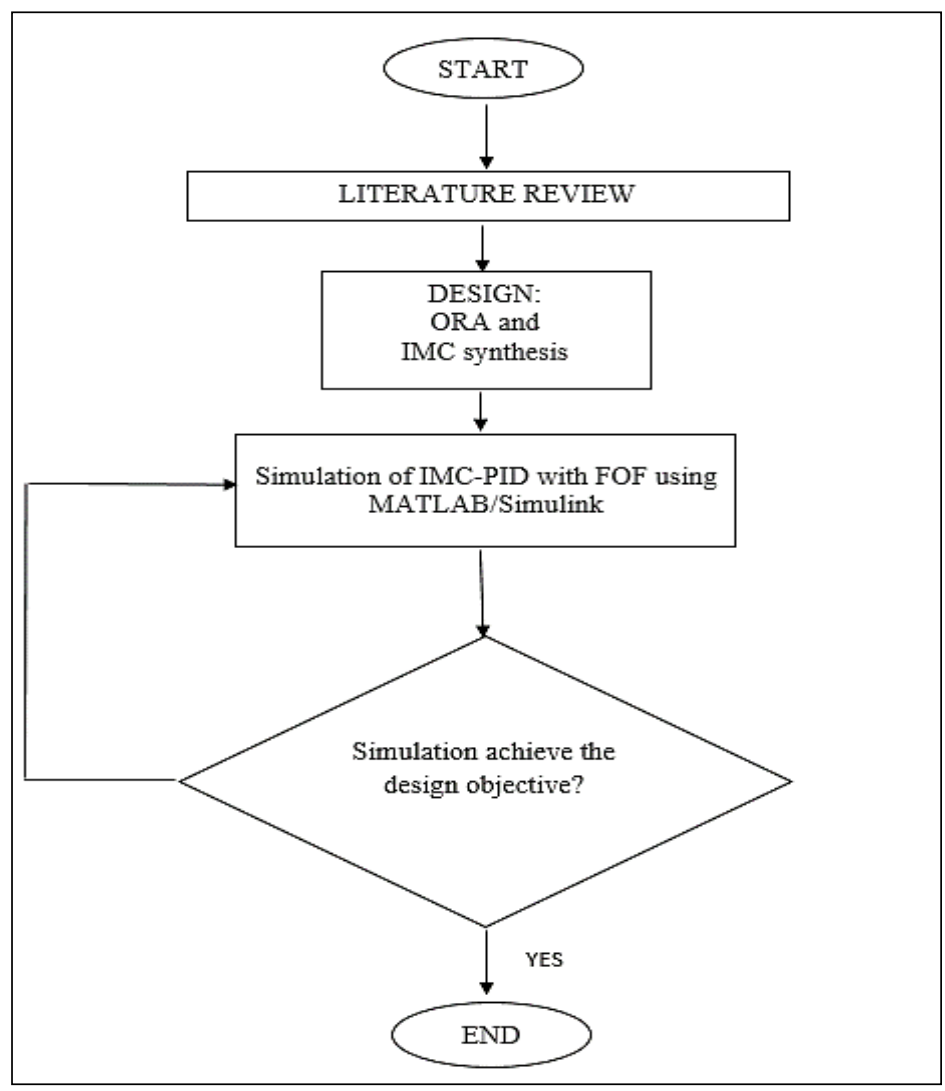

Figure 1. Flow chart of controller design

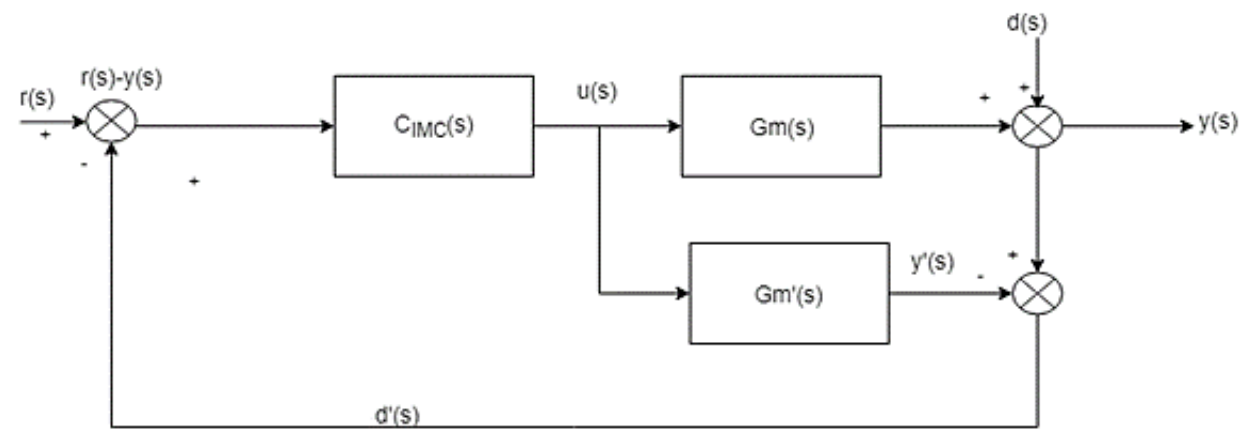

Figure 2. Basic IMC structure

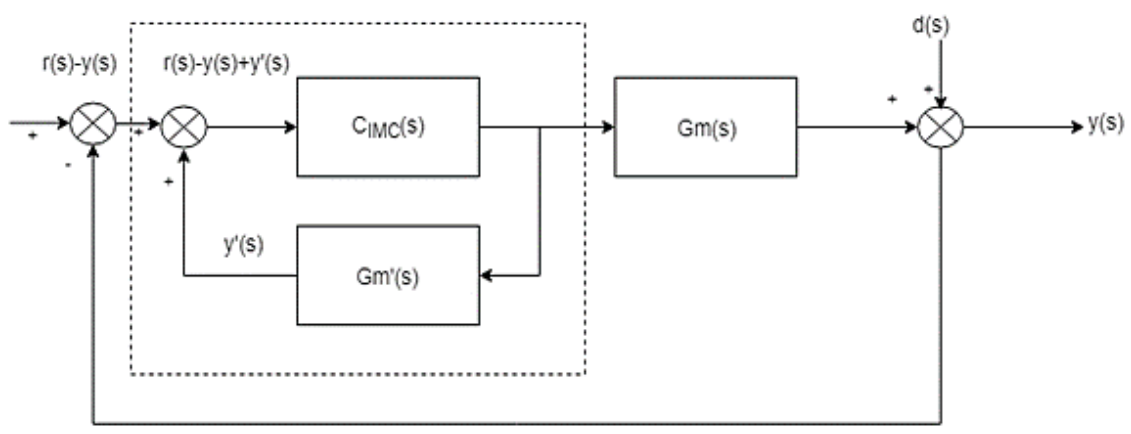

Figure 3. IMC structure's rearrangement 


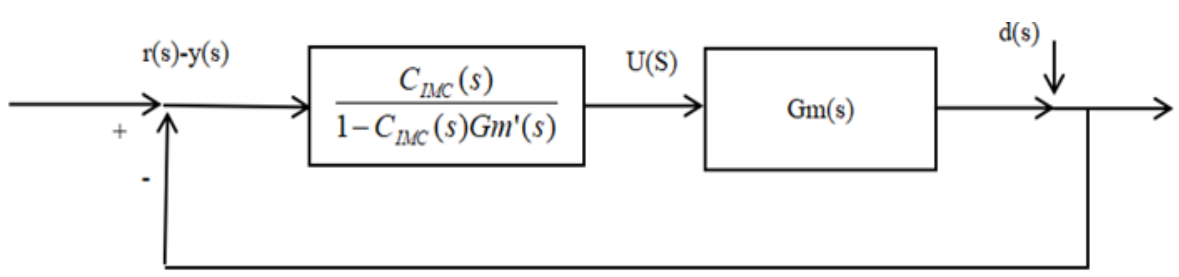

Figure 4. Simplified IMC structure

In consequence, the standard feedback controller yields using IMC structure is given in (1).

$$
C(s)=\frac{C_{I M C}(s)}{1-C_{I M C}(s) G_{m}^{\prime}(s)}
$$

This study applies Bode ideal principle as proposed by Bettayeb and Mansouri in tuning the IMC controller. It is based on an ideal shape of an open loop transfer function in the form,

$$
L(s)=\frac{1}{\tau_{c} s^{\alpha}}
$$

where the gain crossover frequency is,

$$
\begin{aligned}
& \omega_{c}=\frac{1}{\tau_{c}^{-\alpha}} \\
& \left|L\left(\omega_{c}\right)\right|=1
\end{aligned}
$$

Hence, the slope of magnitude curve which on $\log -\log$ scale is parameter of $\alpha$. It is assumes that integer value as well as non-integer value. The value of $\alpha$ in transfer function of $\mathrm{L}(\mathrm{s})$ is fractional-order differentiator when $\alpha<0$ and fractional integrator when $\alpha>0$. The bode diagram is simple where the amplitude curve is straight line of constant slope $-20 \alpha \mathrm{dB} / \mathrm{dec}$ where the phase margin can be derived as (4).

$$
\varphi_{m}=\pi(1-\alpha / 2)
$$

Considering the unity feedback system shown in Figure 3, if the forward transfer function is equal to $\mathrm{L}(\mathrm{s})$, then $\mathrm{L}(\mathrm{s})$ will determine the property of the closed-loop system. Phase margin will remain equal even though there are changes in system gain. The closed loop system of Figure 4 is same as given by at (1). While the desired closed loop transfer function is given by,

$$
F(s)=\frac{L(s)}{1+L(s)}=\frac{1}{1+\tau_{c} s^{\alpha}}
$$

As shown in (5) is used as a reference model for tuning the controller $\mathrm{C}(\mathrm{s})$. Based on this reference model, the overshoot which depends on $\alpha$ and the settling time which depends on $\tau_{\mathrm{c}}$ can be determined respectively.

\subsection{IMC PID with fractional-order filter}

In this section, the derivation of IMC PID with fractional-order filter will be discussed. The idea of this design is to have an integer-order PID that is cascaded with fractional-order filter to meet closed loop specifications. The general equation of such controller is given by,

$$
c(s)=H(s) \cdot k_{p}\left(1+\frac{1}{\tau_{i} s}+\tau_{d} s\right)
$$

where $\mathrm{H}(\mathrm{s})$ is a fractional-order filter. The PID parameter such as $\mathrm{K}_{\mathrm{p}}$ is the gain, $\mathrm{T}_{\mathrm{i}}$ is the integral time constant and $\mathrm{T}_{\mathrm{d}}$ is derivative time constant. If we consider a first-order plus dead-time system, 
$G(s)=\frac{k_{p} e^{-\epsilon}}{\tau_{p} s+1}$

To simplify, we substitute the dead-time, $\theta$ with first-order Pade' approximation expressed by,

$$
e^{-\theta s}=\frac{1-0.5 \theta s}{1+0.5 \theta s}
$$

Then, substitute (8) into (7) yields,

$$
G(S)=\frac{k_{p}(1-0.5 \theta s)}{\left(\tau_{p} s+1\right)(1+0.5 \theta s)}
$$

The transfer function in (9) can be factorized into the invertible and non-invertible elements where the $\mathrm{G}_{\mathrm{m}}{ }^{\text {}+}(\mathrm{s})$ contains time delay and right-half plane zeros while $\mathrm{Gm}^{\text {'- }}$ (s) contains zero at left-half plane. The equation is describe as follows,

$$
\begin{aligned}
{G_{m}}^{\prime-}(s) & =\frac{k_{p}}{\left(\tau_{p} s+1\right)(1+0.5 \theta)} \\
{G_{m}}^{\prime+}(s) & =-0.5 \theta s+1
\end{aligned}
$$

Then, a perfect control can be achieved with the idealized controller which is in term of the inverse of process model with fractional-order filter $H(s)$, as follow,

$$
C_{I M C}(s)=\frac{1}{G_{m}{ }^{\prime}-(s)} H(s)
$$

In order to obtain the stability of controller and desirable of iso-damping properties, $H(s)$ is represented by $L(s)$ in fractional-order,

$$
H(s)=\frac{1}{1+\tau_{c} s^{\alpha+1}} \quad ; 0<\alpha<1
$$

The fractional property of the controller represented by fractional reference model $\mathrm{H}(\mathrm{s})$ given in (13) where the parameter $\tau_{\mathrm{c}}$ is time constant and $\alpha$ are chosen to impose phase margin and crossover frequency, $\omega_{\mathrm{c}}$ of closed loop. Next, substitute (13) into (12). Hence, the IMC controller with fractional filter is given by,

$$
C_{I M C}(s)=\frac{\left(1+\tau_{p} s\right)(1+0.5 \theta)}{k_{p}}\left[\frac{1}{\left(1+\tau_{C} s^{\alpha+1}\right)}\right]
$$

where $\alpha$ is the parameter of fractional order and $\tau_{\mathrm{c}}$ is the closed- loop time constant. Then, substitute (14) into (1) and expand the equation to get (16),

$$
\begin{aligned}
& C_{I M C}(s)=\frac{\left(1+\tau_{p} s\right)(1+0.5 \theta)}{k_{p}\left(1+\tau_{c} s^{\alpha+1}\right)} \\
& C(s)=\frac{0.5 \theta \tau_{p} s^{2}+\left(0.5 \theta+\tau_{p}\right) s+1}{k\left(\tau_{c} s^{\alpha}+0.5 \theta\right) s}
\end{aligned}
$$

Compare (16) to (6) to get the ideal PID controller as below,

$$
C(s)=\frac{1}{1+\frac{2 \tau_{c}}{\theta} s^{\alpha}} \frac{2 \tau_{p}+\theta}{k_{p} \theta}\left(1+\frac{1}{\frac{2 \tau_{p}+\theta}{2}} s+\frac{\tau_{p} \theta}{2 \tau_{p}+\theta} s^{2}\right)
$$


Hence, the tuning parameter of an ideal PID controller based IMC strategy can be obtain by

$$
\begin{gathered}
k_{c}=\frac{2 \tau_{p}+\theta}{k_{p} \theta} \\
\tau_{i}=\frac{2 \tau_{p}+\theta}{2} \\
\tau_{d}=\frac{\tau_{p} \theta}{2 \tau_{p}+\theta}
\end{gathered}
$$

The fractional-order filter parameter from (13) that given in (19)

$$
\begin{aligned}
& \alpha=\frac{\pi-\varphi m}{\frac{\pi}{2}}-1 \\
& \tau_{c}=\frac{1}{\omega_{c}^{\alpha+1}}
\end{aligned}
$$

Table 1 shows the calculated value of $\alpha$ and time constant $\tau_{\mathrm{c}}$ calculated using (19) for a desired phase margin and crossover frequency while the Bode plot is shown in Figure 5. Crossover frequency $\omega_{\mathrm{c}}$ is constant value of 0.008 which one of the controller design criteria in [25]. As stated in (13), value of $\alpha$ is between 0 to 1 . When $\alpha$ more than 1 , the time constant $\tau_{\mathrm{c}}$ gave the slowest response among other value $\alpha$.

Table 1. Desired value of open loop reference

\begin{tabular}{cccc}
\hline $\begin{array}{c}\text { Phase margin, } \\
\text { (open loop reference model) }\end{array}$ & $\begin{array}{c}\text { Crossover } \\
\text { frequency, } \omega_{\mathrm{c}}\end{array}$ & Alpha, $\alpha$ & $\begin{array}{c}\text { Time } \\
\text { constant, } \tau_{\mathrm{c}}\end{array}$ \\
\hline 170 & 0.008 & 0.1111 & 213.74 \\
160 & 0.008 & 0.2222 & 365.47 \\
150 & 0.008 & 0.3333 & 624.90 \\
140 & 0.008 & 0.4444 & 1068.51 \\
80 & 0.008 & 1.1111 & 26716.94 \\
60 & 0.008 & 1.3333 & $78,112.4$ \\
\hline
\end{tabular}

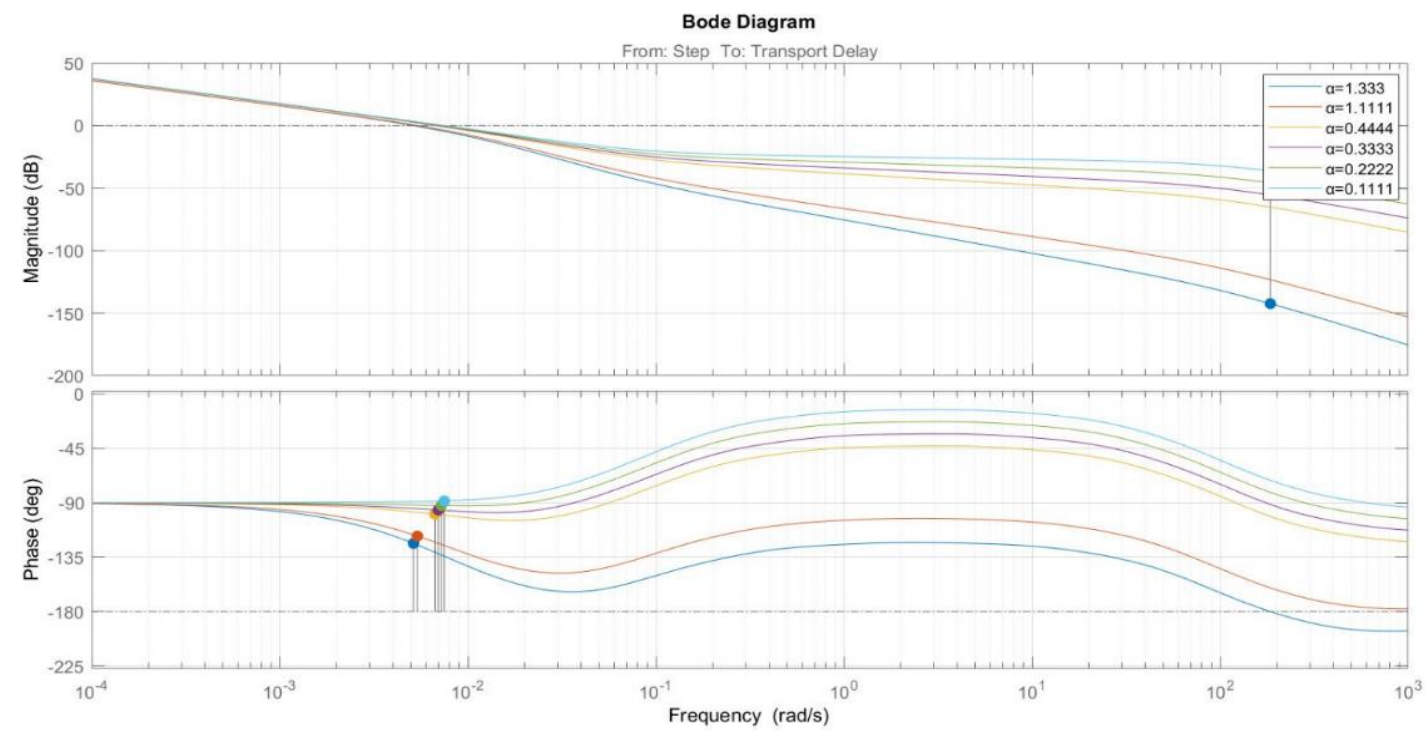

Figure 5. Bode plot of open loop reference 
Figure 5 shows the Bode plot of open loop reference by using ORA that using varies values of $\alpha$. When the value of $\alpha$ varied, it give us desired value phase margin and crossover frequency that will use to calculate the fractional order filter at (19).

\section{RESULTS AND DISCUSSION}

In this study, block diagram of the proposed method has been designed in MATLAB/Simulink software. The step input signal has been set from 0 to 15 to represent the temperature from $70^{\circ} \mathrm{C}$ to $85^{\circ} \mathrm{C}$. The PID controller block is set according to the parameter of $\mathrm{K}_{\mathrm{c}}=5.2, \mathrm{~T}_{\mathrm{i}}=1 / 292.5$ and $\mathrm{T}_{\mathrm{d}}=62.64$ using formula in (18). Besides that, the controller consist of fractional filter have been cascaded with IMC-PID block diagram. The cascaded block diagram used to impose the phase margin and crossover frequency by using the value of parameter $\alpha$ and $\tau_{\mathrm{c}}$. The step response of IMC-PID with fractional-order filter controller was compared based on the parameter where the block diagrams for all tuning are the same. Table 2 shows the result where there is a fractional characteristic of the open loop system. In this case, adjust the magnitude (gain) to increase the crossover frequency by 1 to achieve the fractional specification.

Table 2. Data for open loop system

\begin{tabular}{ccc}
\hline Alpha, $\alpha$ & $\begin{array}{c}\text { Phase } \\
\text { margin, } \varphi_{\mathrm{m}}\end{array}$ & $\begin{array}{c}\text { Crossover } \\
\text { frequency, } \omega_{\mathrm{c}}\end{array}$ \\
\hline 0.1111 & 165 & 1.02 \\
0.2222 & 155 & 1.00 \\
0.3333 & 145 & 1.04 \\
0.4444 & 135 & 0.98 \\
1.1111 & 75.5 & 1.01 \\
1.3333 & 55.6 & 0.93 \\
\hline
\end{tabular}

Based on Figure 6 shows the bode plot of the open-loop system represents for other value of alpha. It shows the difference of the result obtained before and after increase the gain to achieve the crossover frequency $\omega c=1 \mathrm{rad} / \mathrm{s}$. In the Bode plot open-loop system, the phase curve is flat around the gain of crossover frequency, $\omega c$ and the system has a phase margin of approximate to the desired value. For example, the closed-loop system of $\alpha=0.1111$ and time constant, $\tau_{c}=213.74 \mathrm{~s}$ have imposed the approximate of phase margin which is $\mathrm{PM}=165^{\circ}$ close to phase margin of open-loop reference $\mathrm{PM}=170^{\circ}$. This observation leads to a conclusion that the controller tune by the proposed method is robust against gain variation and having isodamping property around the gain crossover frequency.

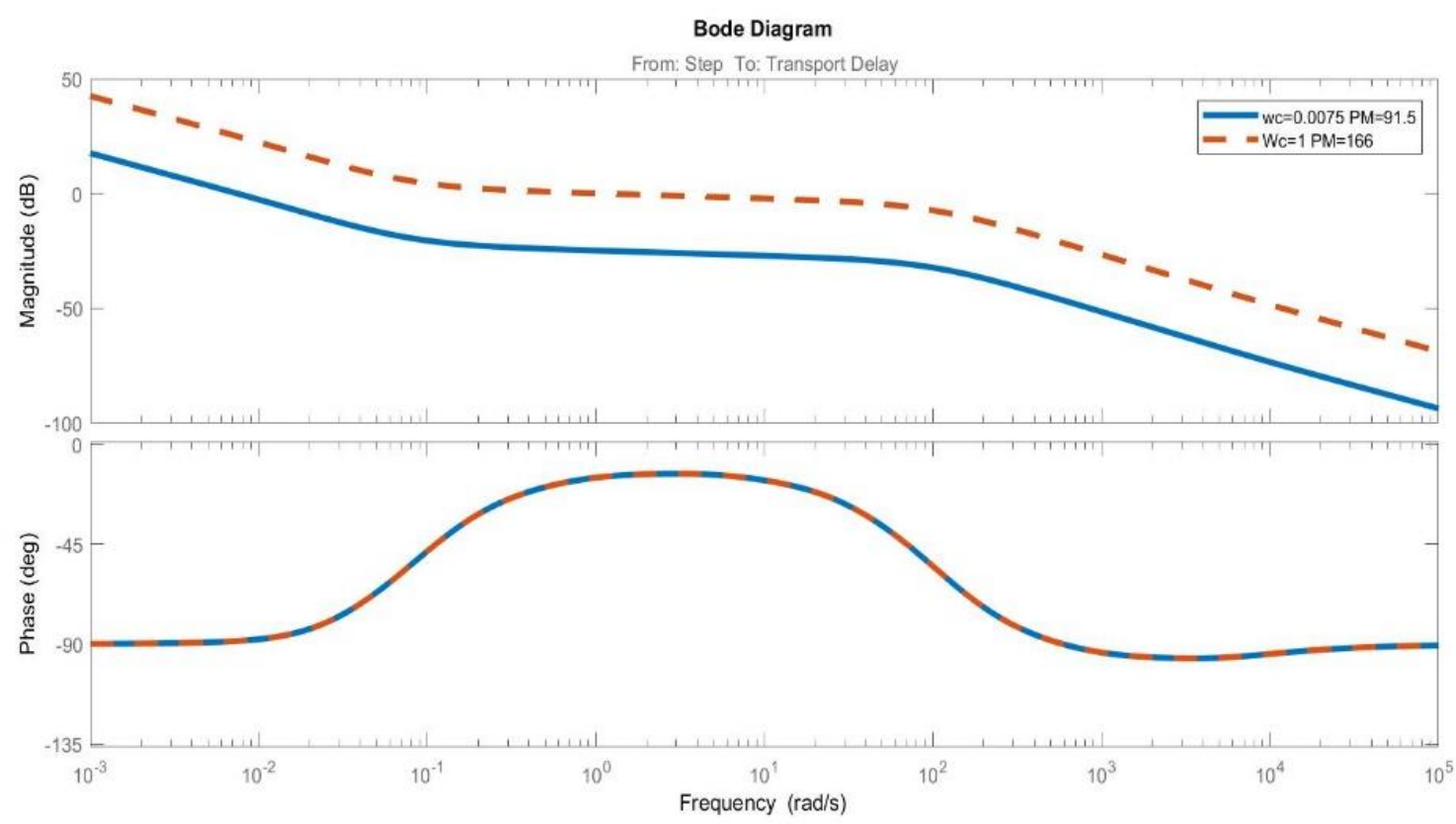

Figure 6. Bode plot of open loop system $\mathrm{a}=0.1111$ 
Table 3 shows the transient response of the IMC-PID fractional-order filter tuning method with varying value of $\alpha$. Based on the result obtain, the highest percentage of overshoot is $12.1 \%$ at $\alpha=1.333$ where the settling time is $T_{\mathrm{s}}=845 \mathrm{~s}$ that is slower than others. The performance of this system was improved at $\alpha=0.3333$ when the overshoot was lower and diminished. The settling time response also improve at $\mathrm{T}_{\mathrm{r}}=461 \mathrm{~s}$. However, the rise time is a bit slower compared to other alpha.

Table 3. Comparison of transient response in various range of alpha, $\alpha$

\begin{tabular}{cccc}
\hline Alpha, $\alpha$ & $\begin{array}{c}\text { Rise } \\
\text { Time }\left(\mathrm{T}_{\mathrm{r}}\right),\end{array}$ & $\begin{array}{c}\text { Settling time } \\
\left(\mathrm{T}_{\mathrm{s}}\right)\end{array}$ & $\begin{array}{c}\text { Overshoot } \\
(\% \mathrm{OS})\end{array}$ \\
\hline 0.1111 & 300 & 517 & - \\
0.2222 & 290 & 490 & - \\
0.3333 & 281 & 461 & - \\
0.4444 & 274 & 431 & 0.056 \\
1.1111 & 257 & 779 & 7.25 \\
1.3333 & 256 & 845 & 12.1 \\
\hline
\end{tabular}

Figure 7 shows the closed-loop system step response. The performance of the closed-loop system obtains from simulation have produced better transient response when $\alpha<1$. Besides that, the percentage of overshoot also has decreased and disappears. However, the rise time, $\mathrm{T}_{\mathrm{r}}$ has a slower response compared to the fast-responding when $\alpha>1$. In terms of settling time $T_{s}$, when $\alpha>1$ has the slowest response due to the overshoot compared to the value of $\alpha<1$ where it has a lower value without overshooting. Based on observation, the lower value of alpha, $\alpha$ with the highest value of phase margin has reduced the overshoot compared to the lower phase margin where it increases the overshoot. Besides, this relation has proved that the percentage of overshoot depends on alpha, $\alpha$ where the settling time depends on the time constant, $\tau_{\mathrm{c}}$.

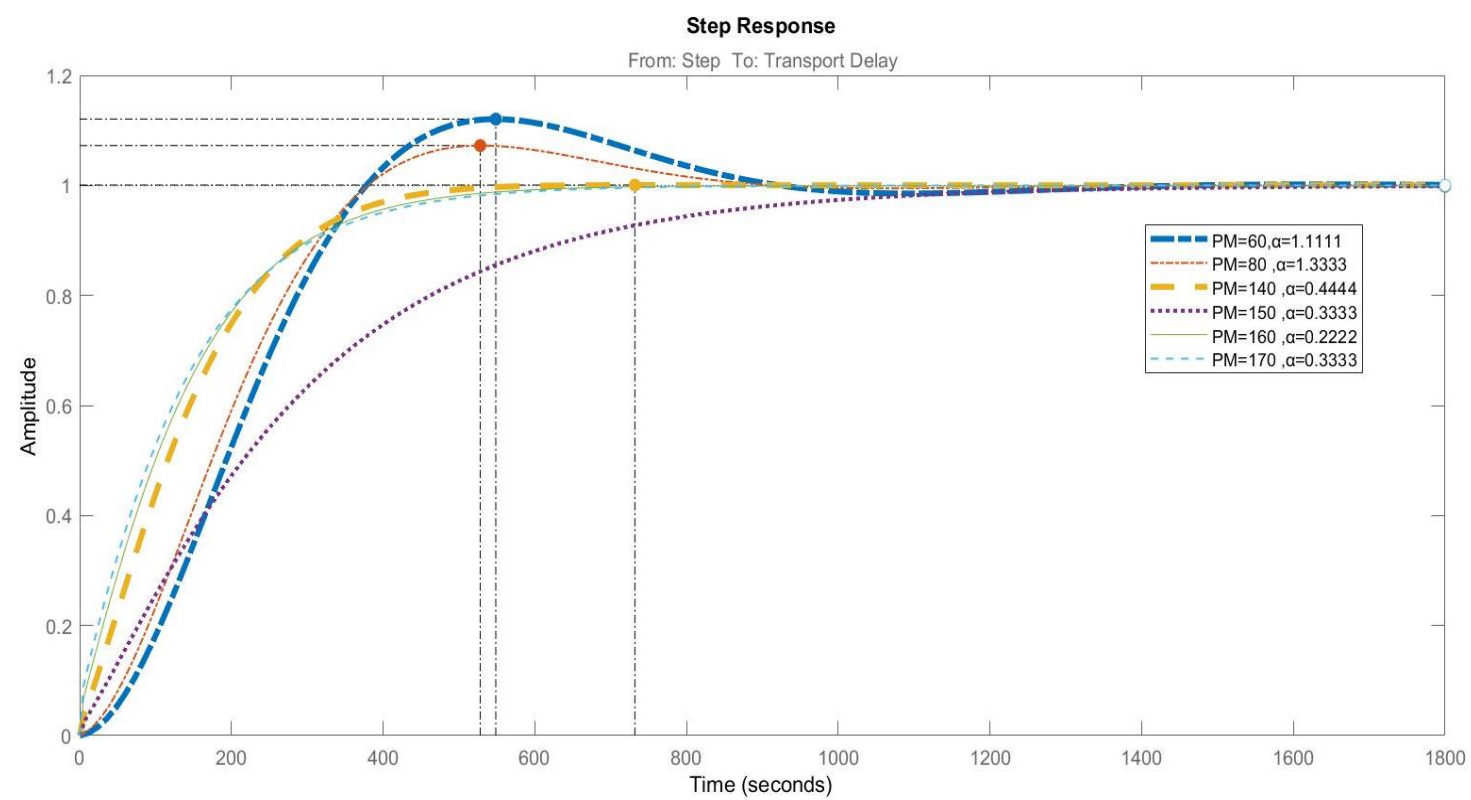

Figure 7. Step response for closed loop system of IMC PID with fractional order filter

\section{CONCLUSION}

This paper presented the IMC-PID controller with fractional-order filter for steam distillation essential oil extraction process. This study aims to design a controller that can control the steam temperature during the extraction. It consists of a conventional PID controller based on an IMC paradigm and cascaded with a fractional-order filter. This proposed method is more attractive than conventional PID as it has the isodamping robustness and more degree of freedom to meet other specification. The parameter of the closedloop step response has been tuned by the simulation to obtain the desired overshoot (depends on $\alpha$ ) and desired settling time (depends on the time constant, $\tau_{\mathrm{c}}$ ). The proposed method has met all the fractional specification and also have better performance of a closed-loop system. 


\section{ACKNOWLEDGEMENTS}

The authors like to express our gratitude to Faculty of Electrical Engineering, Universiti Teknologi MARA Shah Alam and IRMI through BESTARI (Reference Code:600-IRMI/DANA 5/3/BESTARI $(049 / 2017)$ internal fund for the funding and facilities.

\section{REFERENCES}

[1] M. Tajjudin, N. Ishak, M. H. F. Rahiman, N. M. Arshad, R. Adnan, and H. Ismail, "Quality assessment of citronella oil with regulated extraction temperature," Proc. - 2012 IEEE Int. Conf. Control Syst. Comput. Eng. ICCSCE 2012, 2013, pp. 602-606.

[2] S. Maharaj and D. McGaw, "Mathematical Model For The Removal Of Essential Oil Constituents During Steam Distillation Extraction," Processes, vol. 8, no. 4, p. 400, 2020.

[3] H. H. A. Rassem, A. H. Nour, and R. M. Yunus, "Australian Journal of Basic Applied Sciences: Techniques For Extraction of Essential Oils From Plants: A Review," Aust. J. Basic Appl. Sci. Aust. J. Basic Appl. Sci, vol. 10, no. 1016, pp. 117-127, 2016.

[4] R. Kowalski, G. Kowalska, J. Jamroz, A. Nawrocka, and D. Metyk, "Effect of the ultrasound-assisted preliminary maceration on the efficiency of the essential oil distillation from selected herbal raw materials," Ultrason. Sonochem., vol. 24, pp. 214-220, 2015.

[5] C. Zhi-ling, C. Jian-ping, C. Hui-lin, and B. Wei-tao, "Research on the Extraction of Plant Volatile Oils," Procedia Environmental Sciences, vol. 8, pp. 426-432, 2011.

[6] S. Hamzeh, R. Safari-Faramani, and A. Khatony, "Effects of Aromatherapy with Lavender and Peppermint Essential Oils on the Sleep Quality of Cancer Patients: A Randomized Controlled Trial," Evidence-Based Complement. Altern. Med., vol. 2020, pp. 1-7, 2020.

[7] S. Ataei, P. Azari, A. Hassan, B. Pingguan-Murphy, R. Yahya, and F. Muhamad, "Essential Oils-Loaded Electrospun Biopolymers: A Future Perspective for Active Food Packaging," Adv. Polym. Technol., vol. 2020, pp. 1-21, 2020.

[8] T. K. T. Do, F. Hadji-Minaglou, S. Antoniotti, and X. Fernandez, "Authenticity of essential oils," TrAC - Trends Anal. Chem., vol. 66, pp. 146-157, 2015.

[9] M. Božović, A. Navarra, S. Garzoli, F. Pepi, and R. Ragno, "Esential oils extraction: a 24-hour steam distillation systematic methodology," Nat. Prod. Res., vol. 31, no. 20, pp. 2387-2396, 2017.

[10] M. Tajjudin, M. Azfar Abdullah Pani, S. A. Aziz, N. Ishak, and R. Adrian, "A study on IMC-based PID for steam distillation process," Proc. - 2018 IEEE Int. Conf. Autom. Control Intell. Syst. I2CACIS 2018, 2019, vol. 17, pp. 133-136.

[11] M. Tajjudin, M. H. F. Rahiman, N. Ishak, H. Ismail, N. M. Arshad, and R. Adnan, "Adaptive Steam Temperature Regulation for Essential Oil Extraction Process,” Int. J. Control Sci. Eng., vol. 2, no. 5, pp. 111-119, 2012.

[12] A. A. Yadav, S. S. Chikate, R. B. Vilat, M. A. Suryawanshi, and G. B. Kumbhar, "International Journal of Advance Engineering and Research Review on Steam distillation : A Promising Technology for Extraction of Essential Oil," Int. J. Adv. Eng. Res. Dev., vol. 4, pp. 667-671, 2017.

[13] N. Kasuan, Z. Yusuf, M. N. Taib, M. H. F. Rahiman, N. Tajuddin, and M. A. A. Aziz, "Robust steam temperature regulation for distillation of essential oil extraction process using hybrid fuzzy-PD plus PID Controller," World Acad. Sci. Eng. Technol., vol. 71, no. 11, pp. 932-937, 2010.

[14] N. Gireesh and G. Sreenivasulu, "Comparison of PI controller performances for a Conical Tank process using different tuning methods," 2014 Int. Conf. Adv. Electr. Eng. ICAEE 2014, 2014, no. 1, pp. 3-6.

[15] H. Sun, M. J. Mnati, M. Nabil Ibrahim, and A. Van Den Bossche, "A Tuning Method for the Derivative Filter in PID Controller with Delay Time,” Proc. 2018 9th Int. Conf. Mech. Aerosp. Eng. ICMAE 2018, 2018, pp. 574-578.

[16] C. Dey, R. K. Mudi, and D. Simhachalam, "A simple nonlinear PD controller for integrating processes," ISA Trans., vol. 53, no. 1, pp. 162-172, 2014.

[17] P. V. G. K. Rao, M. V. Subramanyam, and K. Satyaprasad, "Study on PID controller design and performance based on tuning techniques," 2014 Int. Conf. Control. Instrumentation, Commun. Comput. Technol. ICCICCT 2014, 2014, pp. 1411-1417.

[18] C. E. Garcia and M. Morari, "Internal Model Control. 2. Design Procedure for Multivariable Systems," Ind. Eng. Chem. Process Des. Dev., vol. 24, no. 2, pp. 472-484, 1985.

[19] C. E. Garcia and M. Morari, "Internal Model Control. A Unifying Review and Some New Results," Ind. Eng. Chem. Process Des. Dev, vol. 21, no. 2, pp. 308-323, 1982.

[20] R. Daniel, M. Morari, and S. Skogestad, "Internal Model Control.4.PID Controller Design," Chem. Eng., vol. 25, no. 1, pp. 252-265, 1988.

[21] X. F. Li, D. J. Ding, Y. G. Wang, and Z. Huang, "Cascade IMC-PID Control of Superheated Steam Temperature based on Closed-loop Identification in the Frequency Domain," IFAC-PapersOnLine, vol. 49, no. 18, pp. 91-97, 2016.

[22] S. Skogestad, "Simple analytic rules for model reduction and PID controller tuning," Model. Identif. Control, vol. 25, no. 2, pp. 85-120, 2004.

[23] C. V. Nageswara Rao and R. Padma Sree, "IMC Based Controller Design for Integrating Systems with Time Delay," Indian Chem. Eng., vol. 52, no. 3, pp. 194-218, 2010.

[24] M. Bettayeb and R. Mansouri, "Fractional IMC-PID-filter controllers design for non integer order systems," Journal of Process Control, vol. 24, no. 4, pp. 261-271, 2014. 
[25] M. Bettayeb and R. Mansouri, "IMC-PID-fractional-order- filter controllers design for integer order systems," ISA Trans., vol. 53, no. 5, pp. 1620-1628, 2014.

[26] F. Merrikh-Bayat, "Rules for selecting the parameters of Oustaloup recursive approximation for the simulation of linear feedback systems containing PI $\lambda \mathrm{D} \mu$ controller," Commun. Nonlinear Sci. Numer. Simul., vol. 17, no. 4, pp. 1852-1861, 2012.

\section{BIOGRAPHIES OF AUTHORS}

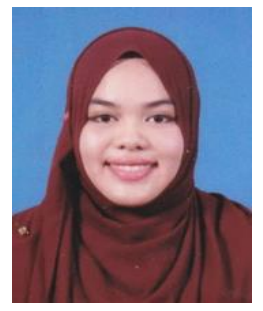

Siti Nur Hasinah Johari was born in Sabah, Malaysia on $27^{\text {th }}$ December 1995. She received the Bachelor of Engineering (B.Eng.Hons.) in Electronics Engineering from Universiti Teknologi MARA (UiTM) in 2019 and currently pursuing Masters Engineering Science (M.Eng.Sc) in Electrical Engineering in the same university. Her major research interests are in the field of essential oil extraction process automation and control focusing on the internal model control.

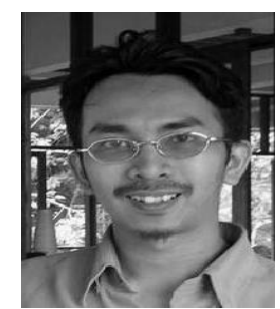

Mohd Hezri Fazalul Rahiman was born in Perak, Malaysia on 22nd February 1978. He received the B.Eng.degree in Electrical (Control and Instrumentation) and the M.Eng. degree in Electrical Engineering from Universiti Teknologi Malaysia (UTM), Skudai, Malaysia, in 2000 and 2002, respectively. He received his $\mathrm{PhD}$ degree in System Identification from Universiti Teknologi MARA (UiTM), Malaysia in 2009. He is currently a senior lecturer at Universiti Teknologi MARA (UiTM), Malaysia. His major interests include essential oil extraction process automation, process control, and system identification.

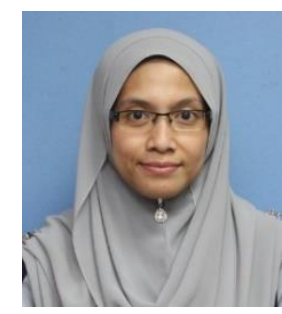

Najidah Hambali received Bachelor of Engineering (B.Eng.Hons.) in Electronics Engineering from Universiti Sains Malaysia (USM) in 2004. In 2005, she joined Universiti Malaysia Pahang (UMP) as a tutor. After received her Masters Engineering Science (M.Eng.Sc.) in Systems and Control from The University of New South Wales (UNSW), Sydney, Australia in 2006, she continued working in UMP as a lecturer until 2010. In January 2011, she joined UiTM and completed her PhD in Advanced Process Control at the Faculty of Electrical Engineering, Universiti Teknologi MARA (UiTM). Currently, she is a senior lecturer in the Centre of System Engineering Studies (CSES), Faculty of Electrical Engineering, UiTM, Shah Alam.

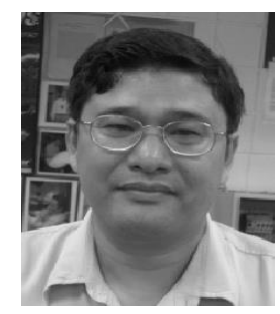

Ramli Adnan was born in Perak, Malaysia on 8 September 1961. He received his B. Sc. In Electrical Engineering from SDSU, South Dakota, USA in 1985 and M.Sc. in Electrical Engineering from Drexel University, Philadelphia, USA in 1993 and PhD in Electrical, Electronic and System Engineering from Universiti Kebangsaan Malaysia (UKM) in 2007. Currently, he is a Professor at Universiti Teknologi MARA, Malaysia. His research interests include Tracking Control, Adaptive Control, System Identification, Flood Prediction using NN and Fractional-Order Controllers. He has been a supervisor to many PhD and MSc students.

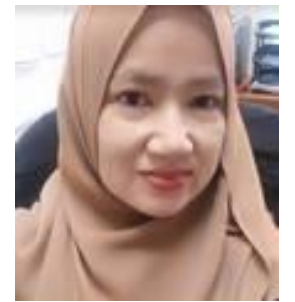

Mazidah Tajjudin was born on 1978. She received the B.Eng. degree in Electrical (Control and Instrumentation) and the M.Eng. degree in Mechatronic and Automatic Control, both from Universiti Teknologi Malaysia (UTM), Skudai, Johor, Malaysia, in 2000 and 2005, respectively. Afterward, she pursuit her $\mathrm{PhD}$ in fractional-order process control at University Teknologi MARA, Malaysia. She is currently a senior lecturer at the same university since 2006. Her major research interests are in the field of essential oil extraction process automation and control focusing on the fractional-order methods. 